\title{
Medical indemnity in state hospitals: Whose baby is it?
}

\section{D A Goonasekera ${ }^{1}$}

Sri Lanka Journal of Child Health 2011; 40: 35-37

(Key words: Medical indemnity; medical litigation)

\begin{abstract}
This case report elucidates medical litigation risks the doctors working in Sri Lankan state hospitals are exposed to but which are due to reasons beyond their control.

\section{Background}

I am placing this case on record considering its relevance to future Sri Lankan doctors defending their innocence in relation to medical negligence, malpractice, incompetence or ignorance in courts of law. There is a rising trend in this country of legal proceedings against individual doctors for malpractice and negligence, sometimes resulting in fines and compensations exceeding their lifetime earnings and savings.
\end{abstract}

\section{Case report}

Recently, I was summoned during my on call shift to see a young girl admitted to the intensive care unit with end stage renal failure (ESRF) following the insertion of an intercostal tube to drain a left haemothorax. The haemothorax had occurred after the insertion of a haemodialysis catheter into her left subclavian vein. Although haemothorax is not an unknown complication associated with this procedure, the process that led to the problem warrants careful analysis.

This young girl in ESRF had been on haemodialysis for two months via a right femoral dual lumen catheter which had later failed and was removed. It was for this reason that she needed a second haemodialysis catheter placement. Having had difficultly in accessing the right, the left subclavian was chosen and an $11 \mathrm{G}$ dual lumen catheter was

${ }^{1}$ Professor in Anaesthesiology, Faculty of Medicine, University of Peradeniya, Sri Lanka

(Received on 10 August 2010. Accepted on 24 September 2010) inserted. Although $11 \mathrm{G}$ was too large a catheter for such a small girl, there was no alternative as the institution did not have any catheters below the size of $11 \mathrm{G}$.

Having had an unsuitable catheter placed in her left subclavian, she not only suffered a haemothorax (probably due to a damaged or split vein) but also developed gross oedema involving the left arm due to venous obstruction or thrombosis. An attempt to haemodialyse her via this catheter also failed as the catheter was malfunctioning. Considerable emotional and physical damage had already occurred as a result.

The next and last option was to place a peritoneal dialysis catheter, again an adult size (as paediatric sizes were not available in the institution) and commence peritoneal dialysis. Sadly, this was also not possible as dialysis fluid was not available due to a shortage. Having seen the adult patient next to her, who was also in acute renal failure with a blood urea of $47 \mathrm{mmol} / \mathrm{L}$ (normal range $3-8 \mathrm{mmol} / \mathrm{L}$ ), receiving a nominal (grossly inadequate) 3 cycles of peritoneal dialysis daily utilizing the 3 bags of peritoneal dialysis fluid provided with greatest difficulty by his relatives, I was not even in a position to discuss the last option, i.e. peritoneal dialysis with the mother of this young girl.

\section{Review}

Sri Lankan citizens are entitled to free health care in government hospitals. However, as government employed doctors we work under stressful conditions, often with extremely limited resources. It is not long ago that a paediatrician was successfully prosecuted for using a sample drug (antibiotic) that was not available in a hospital pharmacy at the time and was found guilty for precipitating an ischaemic forearm due to an inappropriate injection. The government in defence successfully argued that it cannot be held responsible for complications resulting from the use of a drug that was not supplied via the state hospital pharmacy. 
It is common practice that doctors request patients' relatives to supply drugs and other material that are not available for patient care in hospital. Often they also use 'physicians' samples on patients, especially to support ones unable to afford purchases outside the hospital. The provisions available within the hospital for consultants to request local purchase of essential medications, when not available, on a case by case basis, are also precarious. The ultimate result is that a patient may not receive the appropriate medication at the appropriate time, or not receive treatment at all, which may have serious implications on outcome, that could even be fatal.

Most government employed doctors in hospitals work without medical defence i.e. protection against any law-suits. They are also not offered any government indemnity. In the recent past, case scenarios such as the one mentioned above have become far too common, where resource limitations force the doctors to deviate from the ideal and impose sub-standard or empirically alternative treatment, often delayed. This is due to the non availability of timely investigations or the best therapeutic option resulting from case overload, poor supplies and the lack of interest or non prioritization of some services by the authorities. In these kinds of settings, although the doctor has fulfilled all criteria of ethical practice, he or she could still be found guilty of malpractice or negligence. The reason for this is because there had been no assessment in proportion, the influence of external factors beyond the control of the doctor, such as supplies, administration, availability of facilities, phenomenal case load, political influences and bureaucracy affecting the doctor's decision making a process that ultimately determines the disease investigation process, the provision of appropriate therapies and patient outcome. In contrast, a doctor may be truly individually liable (depending on the circumstances) for things such as prescribing experimental drugs and performing cosmetic surgery.

The litigation risk for specialists (consultants) is worse. They work in teams and depend on their team members (juniors) to maintain services at the required standard. A consultant is answerable for mishaps or errors made by their juniors, with or without his or her knowledge, and are usually called for explanation and disciplinary enquires where the consultant-in-charge becomes the first defendant. Yet, the consultants have no authority whatsoever to hire or fire the juniors although they are expected to be fully responsible for what their juniors do. Similarly, the individual doctors have little say in purchasing medications or equipment of their choice for their units as all purchases are made in bulk and often influenced by extraneous factors including politics. However, in the event of a mishap, the politicos and administrators will be swift to blame officers working at the grass root level and pursue enquiries and disciplinary procedures to find a 'scapegoat' amongst them.

\section{Discussion}

Medical malpractice ${ }^{1}$ is professional negligence by act or omission by a health care provider in which care provided deviates from the accepted standards of practice in the medical community and causes injury or death to the patient. In Sri Lanka, most medical professionals are employed in the National Health Service and they have no professional liability insurance to offset the risk and costs of law-suits based on medical malpractice.

In medical malpractice claims, the plaintiff is the patient or, in the case of a wrongful-death suit, the executor or administrator of a deceased patient's estate. The defendant is the health care provider. Although a 'health care provider' usually refers to a physician, the term includes any medical care provider. Relying on vicarious liability or direct corporate negligence, claims may also be brought against hospitals, hitherto a rarity in Sri Lanka.

In a malpractice law-suit, the plaintiff must establish four elements for the tort of negligence ${ }^{2}$.

1. A duty was owed: a legal duty exists whenever a hospital or health care provider undertakes care or treatment of a patient.

2. A duty was breached: the provider failed to conform to the relevant standard of care. The standard of care is proved by expert testimony or by obvious errors (the doctrine of res ipsa loquitur or the thing speaks for itself).

3. The breach caused an injury: The breach of duty was the proximate cause of the injury.

4. Damages: Without damages (losses which may be pecuniary or emotional), there is no basis for a claim, regardless of whether the medical provider was negligent or not. Likewise, damages can occur without negligence, for example, when someone dies from a fatal disease.

The fact of the matter is that in a law-suit, (a) the duty owed is not assessed in proportion to the work load or parallel commitments that doctor had (b) the breach of duty is not assessed in accordance with the extraneous factors that would have forced the doctor 
not to perform to the expected standard. This weakness leads to eventual assumption that the doctors are responsible for the breach in practice that caused injury and therefore is bound to pay the damages.

\section{Conclusion}

The medical community in Sri Lanka, especially those who are employed in the Ministry of Health, needs to understand and address these issues directly and recognize the daily risks they are exposed to in their medical practice. They need to lobby and pressurize the government to provide medical indemnity for all medical officers working in hospitals frequently in environments that are risky, sub-standard and overloaded. There is no doubt that the availability of resources and patient load has much to do with the complications that follow and it is not the sole responsibility of the consultant or the doctor-in-charge and most such environmental factors are beyond his or her control. Thus, in all medical malpractice claims, the Ministry of Health would have to take its quota of responsibility and offer medical indemnity to all its doctors working in conditions in which optimal treatment is not possible. Another option would be to establish a 'no-fault' compensation scheme ${ }^{3}$.

\section{Acknowledgement}

The author gratefully appreciates the assistance provided by Mr. Mahes Salgado in preparation of this manuscript.

\section{References}

1. Medical malpractice: From Wikipedia, the free encyclopedia URL:

http://en.wikipedia.org/wiki/Medical_malpractic e\#cite note- 0

2. The four elements of medical malpractice. Yale New Haven Medical Center: Issues in risk management. 1997. URL:

http://info.med.yale.edu/caim/risk/malpractice/m alpractice_2.html

3. Ruwanpura R. Litigation against medical practitioners: facts and myths. Galle Medical Journal 2009; 14(1): 56-8. 